\title{
Effects of a comprehensive educational group intervention in older women with cognitive complaints: A randomized controlled trial
}

Citation for published version (APA):

Hoogenhout, E., De Groot, R., Van der Elst, W., \& Jolles, J. (2012). Effects of a comprehensive educational group intervention in older women with cognitive complaints: A randomized controlled trial. Aging \& Mental Health, 16(2), 135-144. https://doi.org/10.1080/13607863.2011.598846

DOI:

10.1080/13607863.2011.598846

Document status and date:

Published: 01/01/2012

Document Version:

Peer reviewed version

\section{Document license:}

CC BY-NC-ND

Please check the document version of this publication:

- A submitted manuscript is the version of the article upon submission and before peer-review. There can be important differences between the submitted version and the official published version of record. People interested in the research are advised to contact the author for the final version of the publication, or visit the DOI to the publisher's website.

- The final author version and the galley proof are versions of the publication after peer review.

- The final published version features the final layout of the paper including the volume, issue and page numbers.

Link to publication

\section{General rights}

Copyright and moral rights for the publications made accessible in the public portal are retained by the authors and/or other copyright owners and it is a condition of accessing publications that users recognise and abide by the legal requirements associated with these rights.

- Users may download and print one copy of any publication from the public portal for the purpose of private study or research.

- You may not further distribute the material or use it for any profit-making activity or commercial gain

- You may freely distribute the URL identifying the publication in the public portal.

If the publication is distributed under the terms of Article 25fa of the Dutch Copyright Act, indicated by the "Taverne" license above, please follow below link for the End User Agreement:

https://www.ou.nl/taverne-agreement

Take down policy

If you believe that this document breaches copyright please contact us at:

pure-support@ou.nl

providing details and we will investigate your claim.

Downloaded from https://research.ou.nl/ on date: 26 Apr. 2023 
EFFECTS OF A COMPREHENSIVE EDUCATIONAL GROUP INTERVENTION IN OLDER WOMEN WITH COGNITIVE COMPLAINTS: A RANDOMIZED

CONTROLLED TRIAL

\section{Esther M. Hoogenhout ${ }^{\mathrm{a}}$}

School for Mental Health and Neuroscience, Department of Psychiatry and Neuropsychology Faculty of Health, Medicine and Life Sciences, Maastricht University, The Netherlands Vitalis Geriatric Healthcare, Eindhoven, The Netherlands

\section{Renate H.M. de Groot}

Centre for Learning Sciences and Technologies, Open University of the Netherlands, Heerlen, The Netherlands

School for Mental Health and Neuroscience, Department of Psychiatry and Neuropsychology, Faculty of Health, Medicine and Life Sciences, Maastricht University, The Netherlands

\section{Wim van der Elst}

School for Mental Health and Neuroscience, Department of Psychiatry and Neuropsychology, Faculty of Health, Medicine and Life Sciences, Maastricht University, The Netherlands

Jelle Jolles

Centre Brain and Learning and AZIRE Research Institute, Faculty of Psychology and Education, VU University, Amsterdam, The Netherlands

\footnotetext{
a P.O. Box 616, 6200 MD Maastricht, The Netherlands. Phone: +31 43 3881038, Fax: +31 433884092

E-mail: e.m.hoogenhout@gmail.com
}

Word count of text (excluding abstract, tables/figures, and reference list) : 3876 


\begin{abstract}
\end{abstract}
OBJECTIVE: The current study presents a new comprehensive educational group intervention that offers psycho-education about cognitive aging and contextual factors (i.e., negative age stereotypes, beliefs, health, and lifestyle), focuses on skills and compensatory behavior, and incorporates group discussion. Its effects were investigated in communitydwelling older women who report normal age-related cognitive complaints.

METHODS: A randomized controlled trial with an experimental and waiting list control condition was carried out in a sample of 50 women aged $60-75$ years. As the main problem of these individuals were perceived cognitive deficits without actual cognitive decrements, metacognition served as the primary outcome measure. Objective cognitive functioning and

35 psychological wellbeing were secondary outcome measures. A double baseline and a followup assessment were carried out.

RESULTS: Participants in the experimental condition reported significantly fewer negative emotional reactions towards cognitive functioning $(U=164.500, p=.004)$. The reported effect size $(\delta=-.473)$ could be interpreted as large.

CONCLUSIONS: This new comprehensive educational group intervention reduces negative emotional reactions towards cognitive functioning, which seems a prerequisite for improved subjective cognitive functioning and wellbeing. It can potentially contribute the wellbeing of an important and large group of older adults.

45 Keywords: cognitive aging, subjective forgetfulness, metacognition, intervention, outcome 


\section{Introduction}

One of the most common complaints of normal aging refers to cognitive changes. The prevalence of such cognitive complaints increases with age (Cargin, Collie, Masters, \& Maruff, 2008; Jonker, Geerlings, \& Schmand, 2000; Minett, Da Silva, Ortiz, \& Bertolucci, 2008; Ponds, Commissaris, \& Jolles, 1997). Such perceived cognitive problems are a source of worry and frustration (Commissaris, et al., 1993), and contribute to a lowered quality of life and decreases in wellbeing (Mol, Van Boxtel, Willems, Verhey, \& Jolles, 2009). Although aging-related decrements in cognitive functions are largely inevitable, the association between cognitive complaints and actual cognitive decline is weak (Kliegel, Zimprich, \& Eschen, 2005; Minett, Dean, Firbank, English, \& O'Brien, 2005; Mol, Van Boxtel, Willems, \& Jolles, 2006). Nevertheless, many people who consider themselves to be forgetful are worried that this may be a sign of a pathological condition such as a degenerative brain disease (e.g., Alzheimer dementia) (Commissaris, et al., 1993). They consequently appeal on specialized and costly healthcare services (e.g., memory clinics) (Comijs, Dik, Aartsen, Deeg, \& Jonker, 2005; Verhey, et al., 2007). There is thus a major challenge to develop effective interventions for this target group.

A dominant view in cognitive aging research is that changes in memory reflect changes in the information-processing system, for example cognitive slowing (Salthouse, 1996) or problems in inhibitory functions (Craik \& Bialystok, 2006; Van Hooren, Valentijn, Bosma, Ponds, Van Boxtel, et al., 2007). This might lead to an incomplete understanding and characterization of cognitive aging (Hess, 2005). For that reason, Hess (2005) argued for a broader consideration of cognitive aging from a life span perspective in which the adaptive nature of cognition as well as contextual factors (e.g., social context, negative stereotyping, personal goal setting, beliefs about aging, health and lifestyle) are taken into account. This 
alternative perspective to cognitive aging is multidimensional and has several implications for the development of interventions for older adults with cognitive complaints or objective decrements in cognitive functions.

Interventions traditionally involved cognitive training, which brings about task and domain specific effects that hardly generalize to subjective cognitive functioning, wellbeing or everyday outcome (Ball, et al., 2002; Floyd \& Scogin, 1997; Rebok, Carlson, \& Langbaum, 2007; Verhaeghen, Marcoen, \& Goossens, 1992; Willis, et al., 2006). It is stated that future intervention studies should find a way to increase awareness and knowledge, decrease negative beliefs, and decrease negative memory-related affect (Floyd \& Scogin, 1997; Hohaus, 2007; Rebok, et al., 2007; Verhaeghen, et al., 1992). This may be achieved by developing interventions with a strong educational focus that promote a more realistic understanding of cognitive aging and relevant contextual factors (e.g., health, lifestyle, beliefs, metacognition), counteract stereotypes and provide compensatory techniques (Floyd \& Scogin, 1997; Hess, 2005; Hohaus, 2007; Lachman, 1991; McDougall, 2009). There are several studies that investigate the effects of such multi-dimensional intervention approaches. These studies vary greatly in content, design and outcome (see for example (Hohaus, 2007; Lachman, Weaver, Bandura, Elliott, \& Lewkowicz, 1992; Mohs, et al., 1998; Stuss, et al., 2007; Troyer, 2001; Valentijn, et al., 2005; Van Hooren, Valentijn, Bosma, Ponds, van Boxtel, et al., 2007; West, Bagwell, \& Dark-Freudeman, 2008; Winocur, et al., 2007). The current study evaluated the effectiveness of a new educational intervention program that has evolved from previous successful intervention studies by our research group (Commissaris, Verhey, \& Jolles, 1996; Valentijn, et al., 2005; Van Hooren, Valentijn, Bosma, Ponds, van Boxtel, et al., 2007). The intervention has a strong educational component and fits the ideas of successful aging as defined by Baltes and Baltes (1990) in the model of selective optimization with compensation. It offers information about cognitive aging and the influence 
of contextual factors (Hess, 2005). It extensively discusses the use of commonly applicable compensatory strategies (Bäckman \& Dixon, 1992; Van Hooren, Valentijn, Bosma, Ponds, van Boxtel, et al., 2007). Furthermore, it incorporates group discussion (Flynn \& Storandt, 1990; Valentijn, et al., 2005) about societal and personal beliefs, negative aging stereotypes (Hess, 2005), and pessimistic and maladaptive attributions (Commissaris, et al., 1993; Lachman \& McArthur, 1986) ${ }^{\mathrm{b}}$.

A randomized controlled trial was carried out in a homogenous sample of older community-dwelling women with cognitive complaints that can be attributed to normal aging. A fundamental premise was that the main problem of this target group was an aging-related perceived cognitive decline that has limited predictive value for actual cognitive losses (Kliegel, et al., 2005; Mol, et al., 2006). As is stated by other researchers it is important to decrease, for example, negative feelings about cognitive functioning (Floyd \& Scogin, 1997; Hohaus, 2007; Rebok, et al., 2007; Verhaeghen, et al., 1992). For that reason, the primary aim of the present study was to investigate whether the intervention effectively did so, thus metacognitive functioning served as a primary outcome measure. Secondly, in order to investigate whether these effects generalized to other domains, the effects on objective cognitive performance and psychological wellbeing were examined.

\section{Methods}

\section{Participants}

Participants were recruited through announcements on a regional radio station, and through advertisements in local and regional weeklies. In order to create a homogenous study sample there were age (i.e., between 60 and 75 years) and sex (i.e., being woman) restrictions

\footnotetext{
${ }^{\mathrm{b}}$ Note that a more extensive overview of traditional cognitive interventions and multidimensional approaches, as well as a detailed description of the intervention's background, content and process evaluation are provided in Hoogenhout, De Groot, and Jolles (2011).
} 
to inclusion. Previous research revealed that people in this age range generally report many cognitive complaints that can be ascribed to normal cognitive aging (Ponds, et al., 1997). The creation of single sex intervention groups has a clinical advantage, because relevant topics and reported everyday cognitive problems differ for men and women (Van Hooren, Valentijn, Bosma, Ponds, van Boxtel, et al., 2007).

Other inclusion criteria were: reporting age-related cognitive complaints and/or concerns about becoming demented (as measured with a semi-structured interview), and good comprehension of the Dutch language. Exclusion criteria were a score of 24 or lower on the Mini-Mental State Examination (Folstein, Folstein, \& McHugh, 1975), the occurrence of any neurological disorder (e.g., stroke or dementia), or any (previous) psychiatric disorder (e.g., major depressive disorder or schizophrenia).

\section{Procedure}

The study was designed as a randomized controlled trial. After screening by telephone, eligible persons were sent an information letter about the intervention study. People who were

135 willing to participate were randomly assigned to an experimental or waiting list control condition. Randomization and allocation were done by computer. All participants then received an individual intake interview. A double baseline cognitive assessment was carried out with about one week in between. Additionally, all participants filled in several questionnaires at baseline. In this way, all variables were measured once (i.e., self-report questionnaires) or twice (i.e., cognitive assessment) at baseline. Within one or two weeks after the baseline assessment, participants in the experimental condition started the four-week intervention. Participants in the control condition were placed on a waiting list for four weeks. Both the cognitive tests and questionnaires were administered to all participants approximately seven weeks after the start of the study (see Figure 1). Participants' 
145 characteristics are listed in Table 2 in the Results section. Assessors were not involved in the interventions. Afterwards, participants in the waiting list control condition were offered the intervention program. All participants were assessed in the Maastricht University Medical Centre. Interventions were offered at a research location at Maastricht University. The medical ethics committee of the Maastricht University Medical Centre approved the study and 150 all participants gave their informed consent.

\section{The intervention program}

The content of the intervention program is listed in Table 1. The 4-week intervention consisted of eight 1.5-hour group sessions, with six to nine participants per group. The 155 intervention was offered in a structured manner and within a standard time frame. Each session started with the evaluation and recapitulation of the content of the previous session $( \pm$ 10 minutes). In addition, homework assignments were discussed and questions were answered ( \pm 10 minutes). Afterwards, several themes and topics were introduced one by one in short blocks, which was supported by a PowerPoint slideshow with handouts ( \pm 40 minutes in total). After each block, beliefs and attitudes with respect to the theme were shared and discussed in the group ( \pm 20 minutes in total). Each session ended with a summary of the session's themes, answering questions and a short preview of the homework assignments $( \pm$ 10 minutes).

\section{Measures}


Metacognitive functioning. The primary outcome measure was metacognitive functioning as assessed with the Maastricht Metacognition Inventory (MMI), a newly developed instrument that has several advantages over existing questionnaires (e.g., its focus on metacognition instead of metamemory). The MMI is a multidimensional questionnaire which consists of four scales, i.e., Ability, Affect, Control, and Strategy. The Ability scale consists of 16 items that measured everyday cognitive failures (e.g., difficulty to carry out two simultaneous tasks). The Affect scale contains 11 items that measured emotional reactions towards everyday cognitive failures (e.g., get annoyed when forgetting something). The Control scale contains 5 items that measured complaints about the sense of control over cognitive functioning (e.g., be unable to preserve oneself from cognitive decline). The Strategy scale contains 11 items that measured the use of compensation strategies (e.g., relate information to something that is known well). All items were rated on a 5-point Likert scale, ranging from 1 (= strongly disagree), to 5 (= strongly agree). Higher scores indicated more everyday cognitive failures, more emotional reactions towards cognitive failures, more complaints about the sense of control over cognitive functioning, or the use of more compensation strategies, respectively.

The psychometric properties of the MMI were shown to be good in a large sample of $N=552$ cognitively healthy older adults (aged 50-95 years). A confirmatory factor analysis provided support for the construct validity of the MMI (i.e., the obtained factor structure was highly consistent with the $a$ priori expected 4 -factor model; RMSEA $=.052,90 \% \mathrm{CI}=.050$ $.055, p=.071)$, and the internal consistency of the items of the four MMI scales was high 190 (Cronbach's alpha coefficients ranged between .74 and .91) (Hoogenhout, Van der Elst, De Groot, \& Jolles, under revision). 
Objective cognitive functioning and psychological wellbeing. Objective cognitive functioning and psychological wellbeing were measured with composite scores in order to increase power and improve ecological validity. For a detailed description of the calculation method see Van der Elst, Van Boxtel, Van Breukelen, and Jolles (2008). In order to control for procedural learning effects in cognitive assessment, only data from the second baseline assessment were used.

The Memory Quotient (MQ) was based on the Visual Verbal Learning Test (VVLT) 200 (Van der Elst, Van Boxtel, Van Breukelen, \& Jolles, 2005), an adaptation to the Rey Verbal Learning Test, that measured the ability to learn new information and the ability to retrieve information from memory. The total score of the first three immediate recall trials (VVLT 13) and the delayed recall score (VVLT delayed) were used to construct the MQ. Parallel versions were used for each assessment. Higher MQ scores indicate better memory 205 functioning.

The Executive functioning and Speed Quotient (ESQ) is a composite cognitive measure that was based on the Stroop Colour Word Test (SCWT), the Concept Shifting Test (CST), and the Letter Digit Substitution Test (LDST) test scores. The SCWT was a measure of interference control and speed of information processing (Van der Elst, Van Boxtel, Van 210 Breukelen, \& Jolles, 2006c). SCWT time (i.e., time needed to complete the third card) and SCWT errors (i.e., number of errors on the third trial) were used to construct the ESQ (Van der Elst, et al., 2008). The CST is adapted from the Trail Making Test and consisted of several subtasks. In each subtask, 16 small circles were grouped in a larger circle. Participants were asked to cross out the items as fast as possible in numerical order (part A), alphabetical order (part B), or alternating (part C). The time to complete each subtest was recorded (Van der Elst, Van Boxtel, Van Breukelen, \& Jolles, 2006a). Shifting score (CST shifting = CSTc $[\mathrm{CSTa}+\mathrm{CSTb}] / 2)$ and the number of errors made in part $\mathrm{C}$ (CST errors) were used to 
construct the ESQ (Van der Elst, et al., 2008). The LDST measured general speed of information processing. Participants were asked to replace randomized letters with appropriate numbers indicated by a key, as quickly and accurately as possible (Van der Elst, Van Boxtel, Van Breukelen, \& Jolles, 2006b). The number of correct substitutions made in 60 seconds (LDST60) was used to construct the ESQ (Van der Elst, et al., 2008). Higher ESQ scores indicate better executive functioning and higher speed.

The Psychological Wellbeing Quotient (PWQ) was calculated using the Centre of 225 Epidemiologic Studies Depression scale (CES-D, total score inverted; Bouma, Ranchor, Sanderman, \& Van Sonderen, 1995), the Neurovegetative Complaints Questionnaire (NCQ, two scale scores inverted; Hoogenhout, Van der Elst, De Groot, Van Boxtel, \& Jolles, 2010) and the mental composite score of the Medical Outcome Study 36-item Short-Form Health Survey (SF-36; Ware, Kosinski, \& Keller, 1994). Higher PWQ scores indicate better psychological wellbeing. The CES-D contained 20 statements concerning depressive symptoms (e.g., feeling lonely) in the week prior to test administration. Participants had to indicate symptom frequency on a 4-point scale, ranging from 'seldom or never' $(=0)$ to 'usually or all the time' $(=3)$. Higher scores indicated more depressive symptoms (Bouma, et al., 1995). The NCQ consisted of two subscales (with 11 and 9 items) that measured neurovegetative/somatic complaints (e.g., heart palpitations) or reactive/emotional complaints (e.g., irritability). Participants had to indicate the frequency of occurrence on a 4-point scale ranging from 1 (= no, never) to 4 (= yes, often). Higher scores indicated more complaints (Hoogenhout, et al., 2010). The SF-36 contained 36 items that can be divided in nine subscales. From a selection of these subscales, a composite for mental wellbeing can be calculated (Sanderman, Arrindell, Ranchor, Eysenck, \& Eysenck, 1995; Ware, et al., 1994). Higher SF-36 mental composite scores indicated better mental wellbeing. 
Other measures. In order to investigate participants' characteristics several background variables were assessed. Educational level was measured on an 8-point ordinal scale, ranging

245 from primary education to university education. Furthermore, information about marital status was collected (married/living together or unmarried). Two subscales of the self-reported Eysenck Personality Inventory (EPQ; Sanderman, et al., 1995) were administered to measure neuroticism (e.g., being emotional unstable), and extraversion (e.g., being talkative). These subscales consisted of 22 and 19 dichotomous items (i.e., $1=$ yes, $0=$ no). Higher scores indicated more neuroticism or extraversion.

\section{Statistical Analyses}

Differences in baseline characteristics between the groups (i.e., experimental and control) were investigated in order to verify whether randomisation was successful. A Oneway Analysis of Variance (ANOVA) was performed for age, and Mann Whitney U tests for educational level, EPQ neuroticism and extraversion and MMSE scores. A Chi-square test was used to analyze marital status. Baseline differences in outcome measures were investigated by performing ANOVA's on baseline scores.

Change scores (i.e., change score $=$ posttest score - pretest score) were calculated for

260 all outcome measures. In case of violation of the normality assumption (as checked with Shapiro Wilks tests), non-parametric Mann Whitney U tests were carried out on relevant change scores. Otherwise, parametric ANOVAs were carried out (with the relevant change score as dependent variable) to investigate differences between the groups. In addition, Cliff's $\delta$ scores were calculated, which are effect size estimates that are less sensitive to violations of

265 the normality assumption. Like Cohen's d effect estimates (Cohen, 1988), Cliff's $\delta$ scores could be interpreted as small $(\delta=.147)$, medium $(\delta=.330)$, or large $(\delta=.474)$ effects 
(Kromrey \& Hogarty, 1998; Leech \& Onwuegbuzie, 2002; Romano, Kromrey, Coraggio, \& Skowronek, 2006).

Consistent with the rules for clinical trials (Altman, et al., 2001), analyses were based

270 on the principle of intention-to-treat. Full application of the intention-to-treat principle was, however, impossible because complete outcome data for participants who dropped-out before the end of the study were not available and could consequently not be analysed. A significance level of .01 was used to adjust for multiple comparisons. All analyses were carried out using PASW 18.0 for Macintosh.

\section{Results}

\section{Recruitment of participants}

Results of recruitment and randomization are given in Figure 1. A total of 108 people were screened for participation. Forty-eight of them were excluded: 28 did not meet inclusion criteria and 20 declined to participate after receiving more information about the intervention and the experiment. The remaining 60 participants were randomly assigned to either the experimental or the waiting-list control group. The experimental group started with 30 participants. Six of them decided to end their participation prematurely, due to logistic problems $(n=3)$, health-related problems $(n=2)$ or lack of interest $(n=1)$. The waiting list control group started with 30 participants, four of whom terminated their participation before the end of the study. The main reasons were health-related problems $(n=3)$ and lack of interest $(n=1)$. This resulted in a total sample of fifty people, twenty-four of whom were experimental and twenty-six were waiting list control participants.

$>>$ Insert Figure 1 about here $<<$ 


\section{Baseline characteristics}

There were no group differences in demographic characteristics, EPQ-scores, and MMSE scores at baseline (see Table 2). Participants who dropped out and participants who 295 accomplished the study only differed in EPQ extraversion scores $(\mathrm{U}=34.000, p=.028)$, with those who dropped out reporting higher Extraversion levels.

$>>$ Insert Table 2 about here $<<$

\section{$300 \quad$ Intervention effects}

Results are presented in Table 3. Shapiro Wilks tests for normality indicated that the normality assumption was violated for the MMI-Affect, MMI-Control, MQ, and ESQ change scores. Consequently, non-parametric Mann Whitney U tests instead of parametric ANOVAs were carried out on these variables. No significant differences in scores at baseline were established between the experimental and waiting-list control group for any of the outcome measures (see Table 3). Analyses on the primary outcome measure (i.e., the MMI scale scores) revealed a significant difference in Affect scores $(\mathrm{U}=164.500, p=.004)$. Relative to their baseline functioning, participants in the experimental group reported less emotional reactions towards cognitive functioning than participants in the control condition immediately

310 after intervention. The reported effect size $(\delta=-.473)$ could be interpreted as large (Leech \& Onwuegbuzie, 2002; Romano, et al., 2006). There were no significant differences between the groups in Ability $(\mathrm{F}(1,49)=.577, p=.451)$, Control $(\mathrm{U}=302.500, p=.852)$, and Strategy $(\mathrm{F}(1,49)=1.713, p=.197)$ scores. Moreover, no significant differences were established in objective cognitive functioning as measured with the Memory Quotient $(\mathrm{U}=229.000, p=$ $315.161)$ and the Executive functioning and Speed Quotient $(\mathrm{U}=274.000, p=.616)$, or 
psychological wellbeing as measured with the Psychological Wellbeing Quotient $(\mathrm{F}(1,49)=$ $.069, p=.794)$.

$>>$ Insert Table 3 about here $<<$

\section{Discussion}

The current study evaluated a new comprehensive educational group intervention in healthy older women with age-related cognitive complaints. A detailed description of its background and content as well as the results of a process evaluation are provided by

325 Hoogenhout, De Groot, and Jolles (2011). Results indicated that participants in the experimental condition reported fewer negative emotional reactions towards cognitive functioning as compared to participants in the waiting list control group immediately after intervention. Effect size estimates (Cliff's $\delta=-.473$ ) suggested that this effect could be interpreted as large (Leech \& Onwuegbuzie, 2002; Romano, et al., 2006). The intervention

330 thus improved an important aspect of metacognition. No statistical significant differences were found for other aspects of metacognition (i.e., everyday cognitive failures, complaints about a low sense of control, and the use of compensation strategies), objective cognitive functioning or psychological wellbeing. It is worth noticing that we included participants who were high performing on cognitive measures (i.e., we included a relatively healthy sample)

335 (Van der Elst, et al., 2005, 2006a, 2006b, 2006c). Nevertheless, reported Cliff's $\delta$ effect size estimates (see Table 3) point to medium effects in the expected direction on, for example, objective memory performance $(\delta=.237)$. With better power obtained by a larger study population this effect will probably show statistical significance (Cohen, 1988).

There are several strengths of our study. First, we carried out a randomized controlled trial with an experimental group and a waiting list control group, which allows us to obtain 
relatively robust results and draw reliable conclusions (Altman, et al., 2001). Note however that our study has several limitations that are common in psychosocial intervention research (e.g., the lack of a third non-specific placebo condition, and lack of blindness of participants and trainers). Second, we included a homogeneous and carefully selected study sample to 345 minimize the influence of inter-individual variability in functioning on group comparisons. It is worth to investigate whether positive effects extend to other target groups, like men, adults aged above 75 years, or individuals with mild cognitive impairment. Third, a common problem in intervention research is a lack of instruments that are sensitive enough to detect relatively small changes in functioning due to intervention (Floyd \& Scogin, 1997; Hohaus, 2007; Mohs, et al., 1998; Verhaeghen, et al., 1992), especially if healthy older adults are included who generally report minor problems and show relatively small cognitive loss (Hess, 2005; Hohaus, 2007). We therefore tried to optimize outcome measurement by using sensitive and ecologically valid cognitive composite scores (Van der Elst, et al., 2008), and by developing a new metacognition instrument (i.e., the MMI) (Hoogenhout, et al., under 355 revision) that had several advantages over existing instruments (e.g., its focus on metacognition instead of metamemory alone). To further optimize the outcome measurements and ecological validity, future studies might include alternative measures of everyday cognitive functioning (e.g., timed instrumental activities of daily living; Owsley, Sloane, McGwin, \& Ball, 2002) Our results were obtained immediately after intervention. In order to investigate whether the effects remain over a considerable amount of time, further research is needed. It has been argued that in the course of time other aspects of subjective cognitive functioning, objective cognitive functioning and/or psychological wellbeing are likely to change secondary to changes in metacognition or subjective cognitive functioning (McDougall, 2009; Van 365 Hooren, Valentijn, Bosma, Ponds, van Boxtel, et al., 2007). Previous studies suggested that 
future intervention studies in healthy older adults with cognitive complaints should focus on decreasing negative beliefs and reducing negative memory-related affect. This goal was only marginally achieved by traditional interventions that primarily focus on cognitive training (Floyd \& Scogin, 1997; Hess, 2005; Hohaus, 2007; Rebok, et al., 2007). Our findings further 370 support evidence that multidimensional interventions with a strong educational focus are effective in doing so. In our opinion, the only program that significantly shared characteristics and content with our intervention was described by Hohaus (2007). She compared an educational intervention that incorporated principles of selection optimization and compensation to an active control condition in twenty versus twenty community-dwelling 375 older adults (aged 56 to 84 years). Significant differences between the groups were reported on measures of objective and subjective memory performance. Contrary to Hohaus (2007), we were able to carry out a randomized controlled trial. Furthermore, we performed a double baseline assessment to be sure that potential significant differences in cognitive outcome were not caused by procedural learning effects.

We consider the intervention a potentially valuable contribution to a relevant health issue in older adults. It may offer an opportunity for relatively low-level treatment and can potentially contribute to the wellbeing of an important and large group of older adults. 


\section{References}

385

Altman, D. G., Schulz, K. F., Moher, D., Egger, M., Davidoff, F., Elbourne, D., et al. (2001). The revised CONSORT statement for reporting randomized trials: explanation and elaboration. Annals of Internal Medicine, 134(8), 663-694.

Bäckman, L., \& Dixon, R. A. (1992). Psychological compensation: a theoretical framework. Psychological Bulletin, 112(2), 259-283.

Ball, K., Berch, D. B., Helmers, K. F., Jobe, J. B., Leveck, M. D., Marsiske, M., et al. (2002). Effects of cognitive training interventions with older adults: a randomized controlled trial. Journal of the American Medical Assocation, 288(18), 2271-2281.

Baltes, P. B., \& Baltes, M. M. (1990). Psychological perspectives on successful aging: the model of selective optimization with compensation. In P. B. Baltes (Ed.), Successful aging: Perspectives from the behavioral sciences (pp. 1-34). Cambridge: Cambridge University Press.

Bouma, J., Ranchor, A. V., Sanderman, R., \& Van Sonderen, E. (1995). Het meten van symptomen van depressie met de CES-D: een handleiding [Measuring symptoms of depression using the CES-D: a manual]. Groningen: Noordelijk Centrum voor Gezondheidsvraagstukken, Rijksuniversiteit Groningen.

Cargin, J. W., Collie, A., Masters, C., \& Maruff, P. (2008). The nature of cognitive complaints in healthy older adults with and without objective memory decline. Journal of Clinical and Experimental Neuropsychology, 30(2), 245-257.

405 Cohen, J. (1988). Statistical power analysis for the behavioral sciences. Hillsdal, NJ: Lawrence Erlbaum Associates.

Comijs, H. C., Dik, M. G., Aartsen, M. J., Deeg, D. J., \& Jonker, C. (2005). The impact of change in cognitive functioning and cognitive decline on disability, well-being, and 
the use of healthcare services in older persons. Results of Longitudinal Aging Study Amsterdam. Dementia and Geriatric Cognitive Disorders, 19(5-6), 316-323.

Commissaris, C. J., Jolles, J., Verhey, F. R., Ponds, R. W., Damoiseaux, V., \& Kok, G. J. (1993). Vergeetachtig of dement? Wie maakt zich zorgen en waarom? [Forgetful or demented? Who worries and why?]. Tijdschrift voor Gerontologie en Geriatrie, 24(4), 144-149.

415 Commissaris, C. J., Verhey, F. R., \& Jolles, J. (1996). A controlled study into the effects of psychoeducation for patients with cognitive disturbances. Journal of Neuropsychiatry and Clinical Neuroscience, 8(4), 429-435.

Craik, F. I., \& Bialystok, E. (2006). Cognition through the lifespan: mechanisms of change. Trends in Cognitve Science, 10(3), 131-138.

420 Floyd, M., \& Scogin, F. (1997). Effects of memory training on the subjective memory functioning and mental health of older adults: a meta-analysis. Psychology and Aging, $12(1), 150-161$.

Flynn, T. M., \& Storandt, M. (1990). Supplemental group discussions in memory training for older adults. Psychology and Aging, 5(2), 178-181.

425 Folstein, M. F., Folstein, S. E., \& McHugh, P. R. (1975). "Mini-mental state". A practical method for grading the cognitive state of patients for the clinician. Journal of Psychiatry Research, 12(3), 189-198.

Hess, T. M. (2005). Memory and aging in context. Psychological Bulletin, 131(3), 383-406.

Hohaus, L. (2007). Remembering to age successfully: evaluation of a successful aging approach to memory enhancement. International Psychogeriatrics, 19(1), 137-150.

Hoogenhout, E. M., De Groot, R. H., \& Jolles, J. (2011). A new comprehensive educational group program for older adults with cognitive complaints: background, content, and process evaluation. Educational Gerontology, 37(1), 51-73. 
Hoogenhout, E. M., Van der Elst, W., De Groot, R. H., \& Jolles, J. (under revision). The Maastricht Metacognition Inventory: Factor structure, reliability and validity, and effects of age, sex, and education.

Hoogenhout, E. M., Van der Elst, W., De Groot, R. H., Van Boxtel, M. P., \& Jolles, J. (2010). The Neurovegetative Complaints Questionnaire in the Maastricht Aging Study: psychometric properties and normative data. Aging and Mental Health, 14(5), 613623.

Jonker, C., Geerlings, M. I., \& Schmand, B. (2000). Are memory complaints predictive for dementia? A review of clinical and population-based studies. International Journal of Geriatric Psychiatry, 15(11), 983-991.

Kliegel, M., Zimprich, D., \& Eschen, A. (2005). What do subjective cognitive complaints in persons with aging-associated cognitive decline reflect? International Psychogeriatrics, 17(3), 499-512.

Kromrey, J. D., \& Hogarty, K. Y. (1998). Analysis Options for Testing Group Differences on Ordered Categorical Variables: An Empirical Investigation of Type I Error Control and Statistical Power. Multiple Linear Regression Viewpoints, 25.

450 Lachman, M. E. (1991). Perceived control over memory aging: developmental and intervention perspectives. Journal of Social Issues, 47(4), 159-175.

Lachman, M. E., \& McArthur, L. Z. (1986). Adulthood age differences in causal attributions for cognitive, physical, and social performance. Psychology and Aging, 1(2), 127-132.

Lachman, M. E., Weaver, S. L., Bandura, M., Elliott, E., \& Lewkowicz, C. J. (1992). Improving memory and control beliefs through cognitive restructuring and selfgenerated strategies. Journal of Gerontology, 47(5), 293-299. 
Leech, N. L., \& Onwuegbuzie, A. J. (2002). A call for greater use of nonparametric statistics. Paper presented at the Annual meeting of the Mid-South Educational Research Association.

McDougall, G. J. (2009). A framework for cognitive interventions targeting everyday memory performance and memory self-efficacy. Family and Community Health, 32(1 Suppl), 15-26.

Minett, T. S., Da Silva, R. V., Ortiz, K. Z., \& Bertolucci, P. H. (2008). Subjective memory complaints in an elderly sample: a cross-sectional study. International Journal of Geriatric Psychiatry, 23(1), 49-54.

Minett, T. S., Dean, J. L., Firbank, M., English, P., \& O'Brien, J. T. (2005). Subjective memory complaints, white-matter lesions, depressive symptoms, and cognition in elderly patients. American Journal of Geriatric Psychiatry, 13(8), 665-671.

Mohs, R. C., Ashman, T. A., Jantzen, K., Albert, M., Brandt, J., Gordon, B., et al. (1998). A study of the efficacy of a comprehensive memory enhancement program in healthy elderly persons. Psychiatry Research, 77(3), 183-195.

Mol, M. E., Van Boxtel, M. P., Willems, D., \& Jolles, J. (2006). Do subjective memory complaints predict cognitive dysfunction over time? A six-year follow-up of the Maastricht Aging Study. International Journal of Geriatric Psychiatry, 21(5), 432441.

Mol, M. E., Van Boxtel, M. P., Willems, D., Verhey, F. R., \& Jolles, J. (2009). Subjective forgetfulness is associated with lower quality of life in middle-aged and young-old individuals: a 9-year follow-up in older participants from the Maastricht Aging Study. Aging and Mental Health, 13(5), 699-705. 
Owsley, C., Sloane, M., McGwin, G., Jr., \& Ball, K. (2002). Timed instrumental activities of daily living tasks: relationship to cognitive function and everyday performance assessments in older adults. Gerontology, 48(4), 254-265.

Ponds, R. W., Commissaris, C. J., \& Jolles, J. (1997). Prevalence and covariates of subjective forgetfulness in a normal population in The Netherlands. International Journal of Aging and Human Development, 45(3), 207-221.

Rebok, G. W., Carlson, M. C., \& Langbaum, J. B. (2007). Training and maintaining memory abilities in healthy older adults: traditional and novel approaches. Journals of Gerontology B Series: Psychological Sciences and Social Sciences, 62 Spec No 1, 5361.

Romano, J., Kromrey, J. D., Coraggio, K., \& Skowronek, J. (2006). Appropriate statistics for ordinal level data: Should we really be using t-test and Cohen's d for evaluating group differences on the NSSE and other surveys? Paper presented at the Annual meeting of the Florida Association of Institutional Research.

Salthouse, T. A. (1996). The processing-speed theory of adult age differences in cognition. Psychological Review, 103(3), 403-428.

Sanderman, R., Arrindell, W. A., Ranchor, A. V., Eysenck, H. J., \& Eysenck, S. B. G. (1995). Het meten van persoonlijkheidskenmerken met de Eysenck Personality Questionnaire (EPQ [Measuring personality traits with the Eysenck Personality Questionnaire $(E P Q)]$. Groningen, The Netherlands: Noordelijk Centrum voor Gezondheidsvraagstukken, Rijksuniversiteit Groningen.

Stuss, D. T., Robertson, I. H., Craik, F. I., Levine, B., Alexander, M. P., Black, S., et al. (2007). Cognitive rehabilitation in the elderly: a randomized trial to evaluate a new protocol. Journal of the Internation Neuropsychologal Society, 13(1), 120-131. 
Troyer, A. K. (2001). Improving memory knowledge, satisfaction, and Functioning, via an education and intervention program for older adults. Aging, Neuropsychology, and Cognition, 8(4), 256-268.

Valentijn, S. A., Van Hooren, S. A., Bosma, H., Touw, D. M., Jolles, J., van Boxtel, M. P., et al. (2005). The effect of two types of memory training on subjective and objective memory performance in healthy individuals aged 55 years and older: a randomized controlled trial. Patient Education and Counseling, 57(1), 106-114.

Van der Elst, W., Van Boxtel, M. P., Van Breukelen, G. J., \& Jolles, J. (2005). Rey's verbal learning test: normative data for 1855 healthy participants aged 24-81 years and the influence of age, sex, education, and mode of presentation. Journal of the International Neuropsychological Society, 11(3), 290-302.

515 Van der Elst, W., Van Boxtel, M. P., Van Breukelen, G. J., \& Jolles, J. (2006a). The Concept Shifting Test: adult normative data. Psychological Assessment, 18(4), 424-432.

Van der Elst, W., Van Boxtel, M. P., Van Breukelen, G. J., \& Jolles, J. (2006b). The Letter Digit Substitution Test: normative data for 1,858 healthy participants aged 24-81 from the Maastricht Aging Study (MAAS): influence of age, education, and sex. Journal of Clinical and Experimental Neuropsychology, 28(6), 998-1009.

Van der Elst, W., Van Boxtel, M. P., Van Breukelen, G. J., \& Jolles, J. (2006c). The Stroop color-word test: influence of age, sex, and education; and normative data for a large sample across the adult age range. Assessment, 13(1), 62-79.

Van der Elst, W., Van Boxtel, M. P., Van Breukelen, G. J., \& Jolles, J. (2008). A large-scale cross-sectional and longitudinal study into the ecological validity of neuropsychological test measures in neurologically intact people. Archives of Clinical Neuropsychology, 23(7-8), 787-800. 
Van Hooren, S. A., Valentijn, S. A., Bosma, H., Ponds, R. W., Van Boxtel, M. P., \& Jolles, J. (2007). Cognitive functioning in healthy older adults aged 64-81: a cohort study into the effects of age, sex, and education. Aging Neuropsychol Cogn, 14(1), 40-54.

Van Hooren, S. A., Valentijn, S. A., Bosma, H., Ponds, R. W., van Boxtel, M. P., Levine, B., et al. (2007). Effect of a structured course involving goal management training in older adults: A randomised controlled trial. Patient Education and Counseling, 65(2), 205-213.

535 Verhaeghen, P., Marcoen, A., \& Goossens, L. (1992). Improving memory performance in the aged through mnemonic training: a meta-analytic study. Psychology and Aging, 7(2), $242-251$.

Verhey, F. R., Ramakers, I., Jolles, J., Scheltens, P., Vernooij-Dassen, M. J., \& Olde Rikkert, M. (2007). Memory clinics in the Netherlands: development since 1998 [Geheugenpoli's in Nederland: ontwikkelingen sinds 1998]. Tijdschrift voor Gerontologie en Geriatrie, 38(5), 237-245.

Ware, J. E., Kosinski, M., \& Keller, S. D. (1994). SF-36 Physical and Mental summary scales: a user's manual. Boston, MA: The Health Institute.

West, R. L., Bagwell, D. K., \& Dark-Freudeman, A. (2008). Self-Efficacy and Memory Aging: The Impact of a Memory Intervention Based on Self-Efficacy. Aging, Neuropsychology, and Cognition, 15, 302-329.

Willis, S. L., Tennstedt, S. L., Marsiske, M., Ball, K., Elias, J., Koepke, K. M., et al. (2006). Long-term effects of cognitive training on everyday functional outcomes in older adults. Journal of the American Medical Association, 296(23), 2805-2814.

550 Winocur, G., Craik, F. I., Levine, B., Robertson, I. H., Binns, M. A., Alexander, M., et al. (2007). Cognitive rehabilitation in the elderly: overview and future directions. Journal of the International Neuropsychological Society, 13(1), 166-171 


\section{Acknowledgements}

555 There are no conflicts of interest affecting this manuscript.

The authors thank Esther Steins and Climmy van den Nieuwenhof for their help in

implementing the intervention. The assistance of Sil Aarts, Annette Joosten and Annelies

Wouters in collecting the data has been highly appreciated. 